\title{
All four coronary arteries arising separately from the right aortic sinus of Valsalva: rare anomaly
}

\author{
Raghvendra Choudhary, ${ }_{1}^{1}$ Aditya Batra, ${ }^{2}$ Vinay Malik, ${ }^{3}$ Kunal Mahajan ${ }^{2}$
}

'Department of Cardiology, Oxygen Hospital, Rohtak, Haryana, India

${ }^{2}$ Department of Cardiology, Holy Heart Advanced Cardiac Care and Research Centre, Rohtak, Haryana, India

${ }^{3}$ Department of Radiodiagnosis, Post Graduate Institute of Medical Sciences, Health Map Rohtak, Rohtak, India

\section{Correspondence to} Dr Kunal Mahajan,

kunalmahajan442@gmail.com, kunalmahajan442@gmail.com

Accepted 23 March 2019

\section{DESCRIPTION}

A 60-year-old man presented with a history of new-onset retrosternal chest pain radiating to both arms for the past 2 days. The resting ECG revealed ST coving with $\mathrm{T}$ inversion in the inferior leads. Cardiac enzymes were also elevated. Echocardiography showed near normal biventricular function; however, minimal hypokinesia of the inferior wall was noted. Diagnosis of non-ST

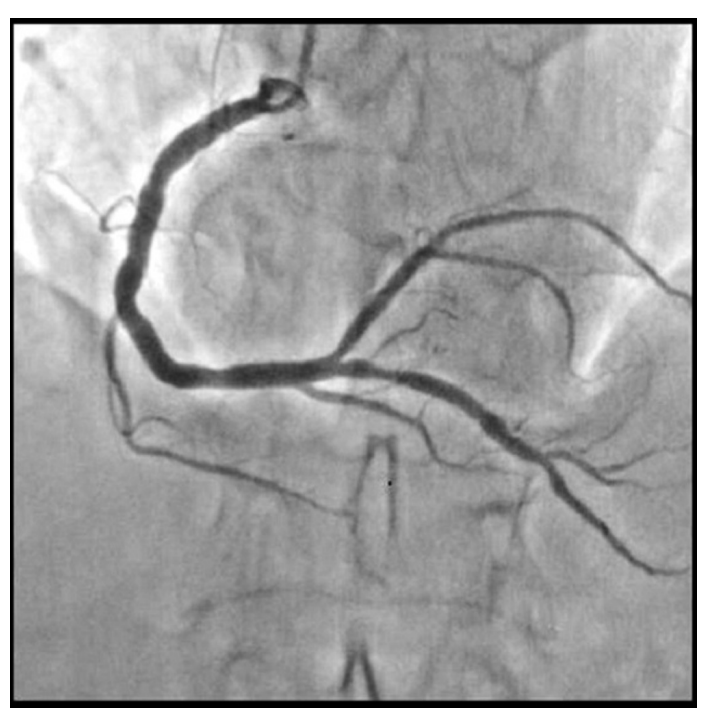

Figure 1 Right coronary artery angiogram.

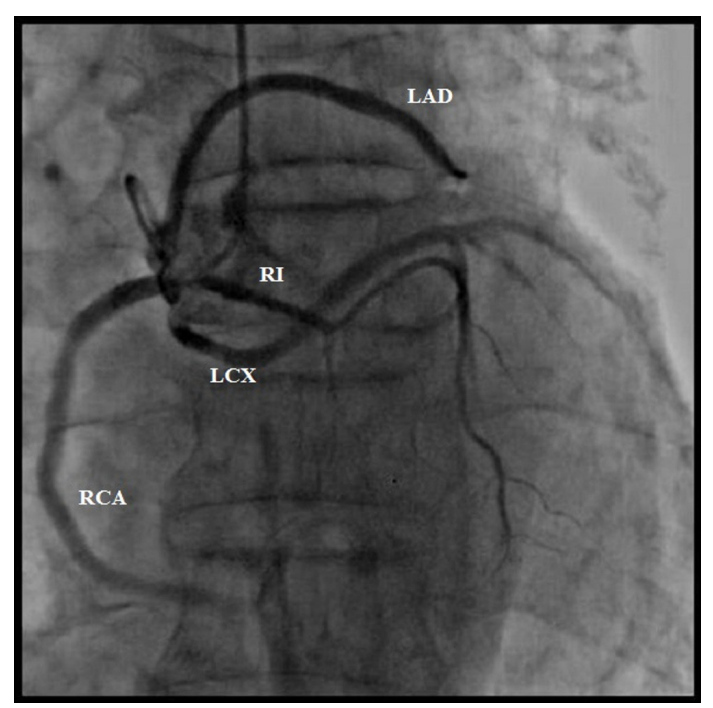

Figure 2 Right aortic sinus injection demonstrating the separate origin of all four coronary arteries. $L A D$, left anterior descending; $L C X$, left circumflex; $\mathrm{RI}$, ramus intermedius; RCA, right coronary artery.

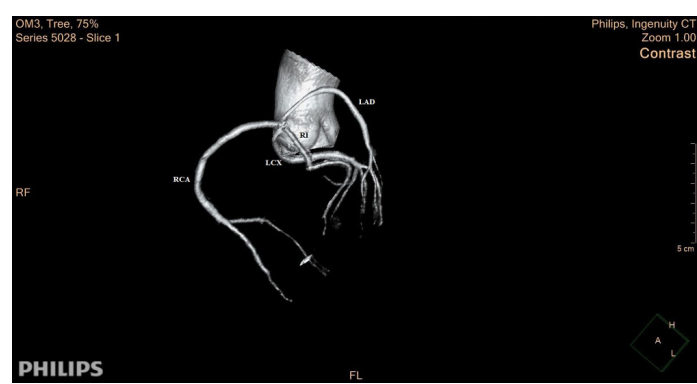

Figure 3 Reconstructed CT coronary angiography showing origin of all four coronary arteries from the right aortic sinus of Valsalva. LAD, left anterior descending; LCX, left circumflex; RI,ramus intermedius; $\mathrm{RCA}$, right coronary artery.

elevation myocardial infarction was made, and the patient was subjected to coronary angiography. The right radial route was selected for coronary angiography. We first cannulated the right coronary artery (RCA), which revealed plaques but no significant obstructive lesion (figure 1). After that, we tried to cannulate the ostium of left coronary artery in the left aortic sinus but failed despite multiple attempts. Then, we performed a non-selective aortic root angiogram, which faintly visualised the origin of a few other vessels near the ostium of RCA. We then kept the Judkin Right diagnostic catheter near the ostium of RCA and injected contrast which revealed anomalously arising left anterior descending (LAD), left circumflex (LCX) and ramus intermedius (RI) coronary arteries, all arising through separate

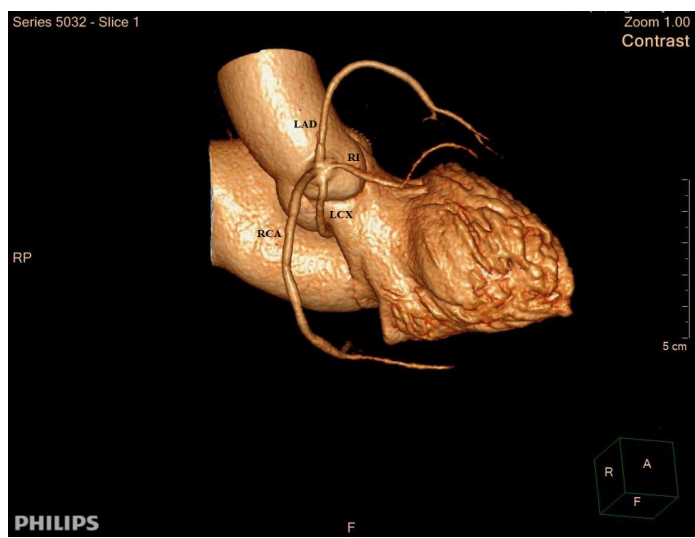

Figure 4 Reconstructed CT coronary angiography showing all four coronary arteries originating separately from the right aortic sinus of Valsalva. LAD, left anterior descending; LCX, left circumflex; RI, ramus intermedius; $\mathrm{RCA}$, right coronary artery. 


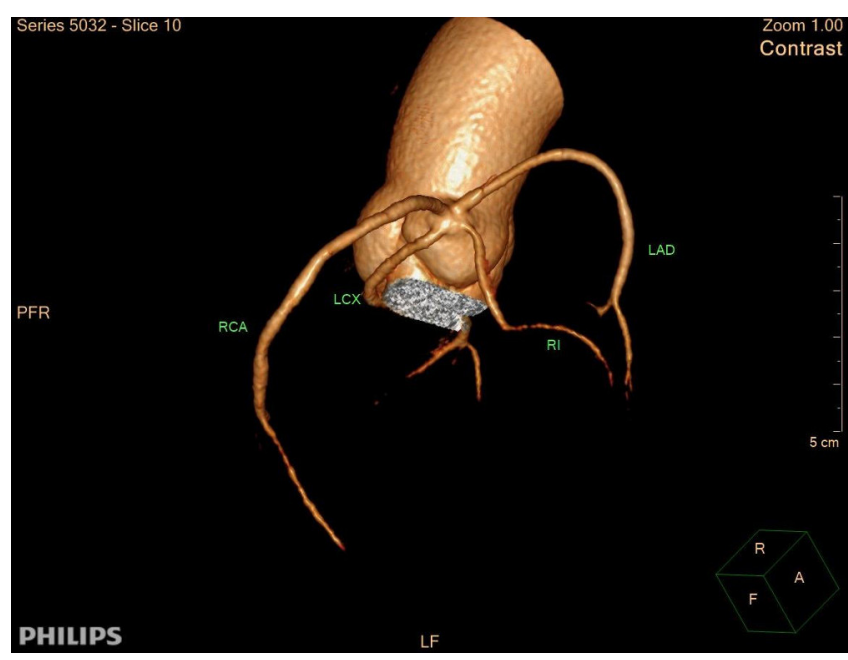

Figure 5 Figure showing all four coronary arteries arising separately from the right aortic sinus of Valsalva. LAD, left anterior descending; LCX, left circumflex; RI, ramus intermedius; RCA, right coronary artery.

Learning points

- The absence of left coronary artery origin from left coronary sinus should make suspicion of anomalous origin of left-sided coronary arteries.

- The origin of all four coronary arteries from four separate ostia is an exceedingly rare anomaly.

- Percutaneous coronary intervention is technically challenging in such cases because of altered ostial configuration and the route of the artery. Appropriate guide selection is mandatory in such cases.

- Angina may occur secondary to the atherosclerotic lesions or because of the compression of the artery while passing between the aorta and the pulmonary artery. ostia from the right aortic sinus of Valsalva (figure 2). None of these arteries revealed any significant obstructive lesions. No coronary intervention was needed. The patient was managed conservatively with high-dose statins, antiplatelet drugs and other recommended therapy. CT coronary angiography was done which confirmed the separate anomalous origin of four coronaries from right sinus and delineated their courses (figures 3-5). LAD and RI followed an anterior course, while LCX was retroaortic in its course. None of the vessels passed between the aorta and the pulmonary artery.

The independent origin of all four coronary arteries (RCA, LAD, LCX and RI) from four separate ostia in the right aortic sinus of Valsalva is an exceptionally rare anomaly. ${ }^{1}$ The course of LAD anterior to the right ventricle or behind the aorta has not been found to be associated with any adverse events. ${ }^{1}$ On the contrary, the course of LAD passing between aorta and pulmonary artery has been associated with an increased risk of ischaemic events and sudden cardiac death. ${ }^{12}$ Recognition of such variations in coronary anatomy is essential since failure to angiographically identify the origin and course of the anomalous coronary arteries can result in inappropriate clinical decisions and complications during coronary angioplasty or cardiac surgery.

Contributors $\mathrm{RC}$ did the coronary angiogram and made the diagnosis. VM provided the $\mathrm{CT}$ images. $\mathrm{KM}$ and $\mathrm{AB}$ wrote the manuscript. All authors read and approved the final version of the manuscript.

Funding The authors have not declared a specific grant for this research from any funding agency in the public, commercial or not-for-profit sectors.

Competing interests None declared.

Patient consent for publication Obtained.

Provenance and peer review Not commissioned; externally peer reviewed.

\section{REFERENCES}

1 Bartorelli AL, Capacchione V, Ravagnani P, et al. Anomalous origin of the left anterior descending and circumflex coronary arteries by two separate ostia from the right sinus of Valsalva. Int J Cardiol 1994;44:294-8

2 Asciutto S, La Franca E, Cirrincione G, et al. Anomalous origin of all three coronary arteries from right sinus of Valsalva. Indian Heart J 2016;68 Suppl 2(Suppl 2):S85-S87.

Copyright 2019 BMJ Publishing Group. All rights reserved. For permission to reuse any of this content visit

https://www.bmj.com/company/products-services/rights-and-licensing/permissions/

BMJ Case Report Fellows may re-use this article for personal use and teaching without any further permission.

Become a Fellow of BMJ Case Reports today and you can:

- Submit as many cases as you like

- Enjoy fast sympathetic peer review and rapid publication of accepted articles

- Access all the published articles

- Re-use any of the published material for personal use and teaching without further permission

For information on Institutional Fellowships contact consortiasales@bmjgroup.com

Visit casereports.bmj.com for more articles like this and to become a Fellow 